\title{
O PALMAR DE COATEPE (QUARAÍ, RS): ENFOQUE FITOGEOGRÁFICO1
}

\author{
JOSÉ NEWTON CARDOSO MARCHIORI² FABIANO DA SILVA ALVES ${ }^{3}$
}

\section{RESUMO}

Descrito apenas em 1995, o palmar de Coatepe é presentemente analisado sob o ponto de vista fitogeográfico e inserido no Distrito do Inhanduvá e Província do Espinhal, segundo a classificação de Cabrera \& Willink. Palavras-chave: Butiá, Butia yatay, Fitogeografia, Palmar de Coatepe, Quaraí, Rio Grande do Sul.

\section{SUMMARY}

[The Coatepe's grove of palm trees, Quaraí - Rio Grande do Sul state (Brazil): a phytogeographic approach].

Described only in 1995, the Coatepe's grove of palm trees is presently analysed under a phytogeographic point of view, beeing inserted in Cabrera \& Willink's Nandubay District and Espinal Province.

Key words: Butia palm, Butia yatay, Phytogeography, Coatepe's grove of palm trees, municipality of Quaraí, Rio Grande do Sul state, Brazil.

\section{INTRODUÇÃO}

Frequentemente confundido com outra espécie do mesmo gênero na literatura sul-riograndense, o butiá-jataí (Butia yatay (Mart.) Becc.) tem como centro de distribuição a Argentina, ocorrendo, ainda, no Uruguai (departamentos de Paysandú e Rio Negro), Paraguai e, no Brasil ${ }^{4}$, apenas no Rio Grande do Sul. Para este Estado, Mattos (1977) e Sobral et al. (2006) restringem a ocorrência ao município de Giruá e à região missioneira, respectivamente. Para Soares \& Witeck Neto (2009), a espécie ocorre na "fronteira da Argentina com o Rio Grande do Sul, bem como no oeste do Uruguai". Lorenzi et al. $(2004,2010)$ por sua vez, indicam para a mesma palmeira a região fronteiriça do Rio

1 Recebido em 27-01-2011 e aceito para publicação em 253-2011.

2 Engenheiro Florestal, Dr. Professor Titular do Departamento de Ciências Florestais, UFSM. Bolsista de Produtividade em Pesquisa (CNPq - Brasil).

3 Biólogo, MSc. Professor da Universidade da Região da Campanha (URCAMP - Alegrete). Doutorando do Programa de Pós-Graduação em Engenharia Florestal, UFSM.

${ }^{4}$ MATTOS, J.R. Palmeiras do Rio Grande do Sul. Roessleria, Porto Alegre, v. 1, n. 1, p. 38.
Grande do Sul com a Argentina e o Uruguai, onde se encontram "densas colônias em solos arenosos". Nenhuma destas referências, todavia, aproxima-se, sequer, da verdadeira distribuição geográfica da espécie no Estado sulino, motivo pelo qual se justifica o presente trabalho, que visa a lançar um novo olhar sobre o tema em foco.

\section{CONSIDERAÇÕES FITOGEOGRÁFICAS}

Descrito somente em $1995^{5}$, o Palmar de Coatepe é a principal área de ocorrência do butiá-jataí no Rio Grande do Sul. Situado a leste da cidade de Quaraí ${ }^{6}$ e no curso médio do arroio Areal (Figura 1), este palmar ocupa parte de uma extensa lente de solos areno-pedregosos, isolada por solos rasos oriundos de rochas vulcânicas, típicos do Planalto da Campanha.

Em primeiro lugar, cabe destacar que esta ocorrência representa uma importante disjunção de Butia yatay (Mart.) Becc., espécie cujo cen-

MARCHIORI, J.N.C.; ELESBÃO, L.E.G.; ALVAREZ FILHO, A. O palmar de Coatepe. Ciência \& Ambiente, Santa Maria, n. 1, p. 93-104, 1995.

6 Em linha reta, o palmar dista $25 \mathrm{~km}$ da sede do município de Quaraí. 


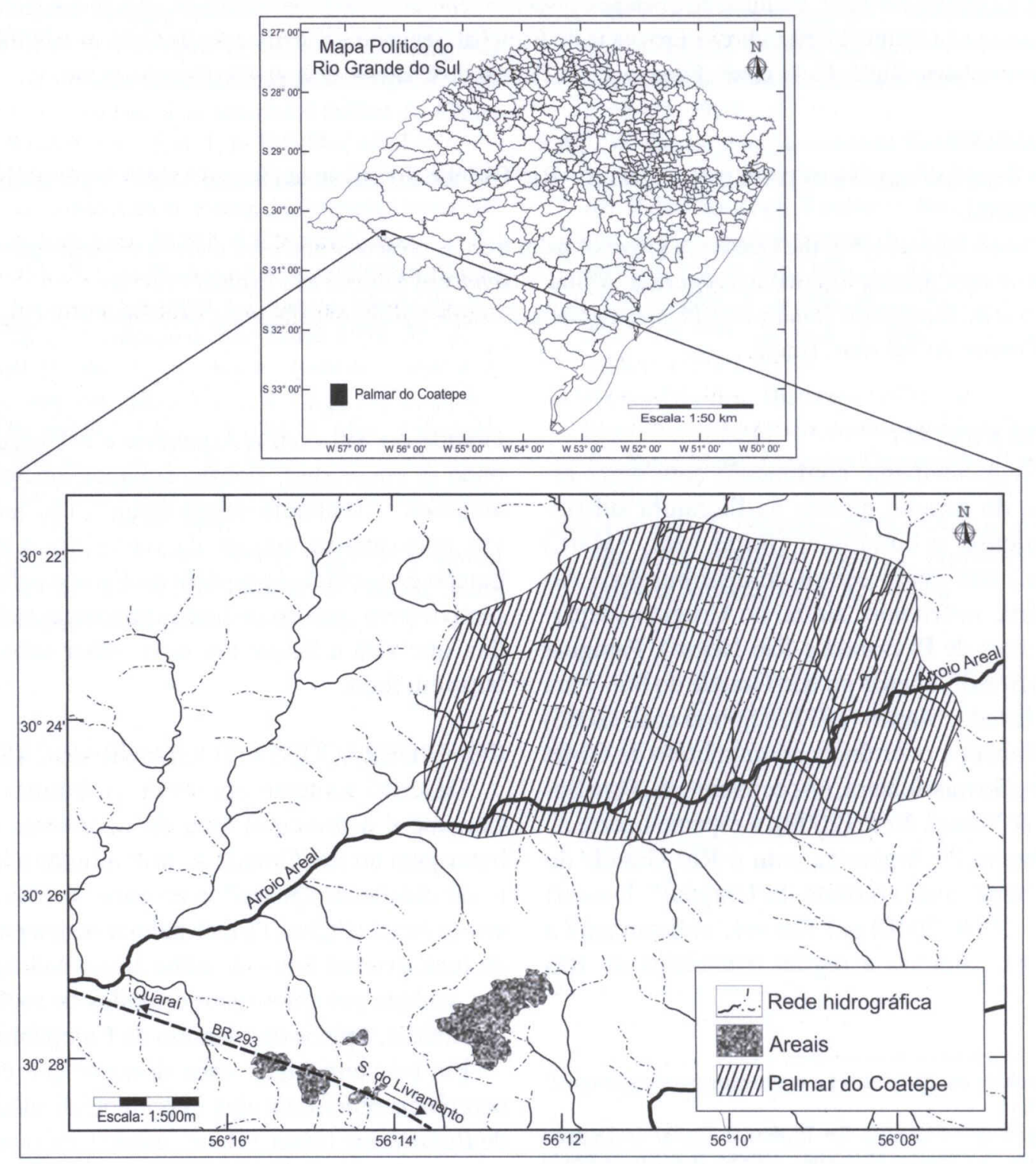

FIGURA 1 - Mapa de localização do Palmar do Coatepe (Quaraí). 
tro de distribuição se encontra na Mesopotâmia argentina (Figura 2), onde constitui uma das comunidades edáficas do Distrito do Inhanduvá e Província do Espinhal, reconhecidos por Cabrera (1951, 1953, 1971) e Cabrera \& Willink (1973).

O local de ocorrência mais conhecido da espécie é o "Palmar Grande", localizado entre as cidades de Berduc e Ubajai (província de Entre Rios), transformado em Parque $\mathrm{Nacional}^{7}$. Na mesma província argentina, destacam-se, ainda, os palmares de Concórdia e, por sua grande extensão, o situado entre as cidades de Federal e Feliciano (Figura 2).

Na província de Corrientes, o jataí se encontra, principalmente, em duas faixas longas, estreitas e com desenvolvimento sudoeste-nordeste (Figura 2). A primeira delas começa ao sul de Mburucuyá e alcança as proximidades de General Paz. Mais longa, a faixa leste tem início ao sul de Goya $\left(29^{\circ} 40^{\prime} \mathrm{S}\right)$ e se estende até as proximidades de Loreto $\left(27^{\circ} 48^{\prime} \mathrm{S}\right)$. A ausência mais a leste desta faixa se explica pela barreira fitogeográfica exercida pelos Esteros de Iberá, vasta área pantanosa existente na metade oriental da referida província argentina.

Por sua proximidade com o Rio Grande do Sul, resta comentar sobre um palmar que acompanha o rio Uruguai, desde Monte Caseros até Paso de Los Libres (Figura 2), onde numerosos indivíduos remanescentes ainda podem ser vistos nos arredores da aduana argentina e ponte internacional. O que chama atenção, neste caso, é a ausência de vegetação semelhante na margem esquerda do Uruguai, nos municípios de Uruguaiana e Barra do Quaraí, fato que se pode atribuir à estreita faixa de solos aluviais existente pelo lado brasileiro, com exceção do "Pontal do Quarâ̂", originalmente revestido, em grande parte, por parques de inhanduvá.

\footnotetext{
Trata-se do "Parque Nacional El Palmar". Ao leitor interessado sobre esta unidade de conservação argentina, recomenda-se: ERIZE, F.; CANEVARI, M.; CANEVARI, P.; COSTA, G.; RUMBOLL, M. Los parques nacionales de la Argentina y otras de sus áreas naturales. Buenos Aires: El Ateneo, 1993. p. 90-92.
}

Ao contrário das planícies da Mesopotâmia argentina, o Palmar do Coatepe se encontra em terreno movimentado, achando-se os butiás no dorso e encostas de colinas. Tais unidades de relevo geralmente apresentam uma camada delgada e bastante intemperizada de rochas vulcânicas, no topo, com base de rochas areníticas, origem do Argissolo Vermelho Distrófico Arênico (Streck et al., 2008), típico da região.

O Palmar do Coatepe ocupa área de aproximadamente $60 \mathrm{~km}^{2}$ (Figura 1), mas com baixa densidade de indivíduos devido à morte paulatina dos butiás mais velhos e ao comprometimento da regeneração natural, exercido pelo gado. Encontram-se, apenas, árvores adultas e de porte mais ou menos uniforme, com estipes de 4 a $8 \mathrm{~m}$ de altura e 20 a $30 \mathrm{~cm}$ de diâmetro (Figura 3). Trata-se, por conseguinte, de uma vegetação muito frágil e susceptível à extinção, se mantidas as atuais condições de uso na área.

A vegetação arbustivo-herbácea tem o capimlimão (Elionurus sp.) como espécie fisionomicamente dominante, destacando-se, ainda, por sua abundância, a quina-do-campo (Discaria americana), o rabo-de-gato (Acalypha brasiliensis), o caraguatá (Eryngium horridum), o turubi (Julocroton argenteus), o barbasco (Buddleja thyrsoides), a grama-forquilha (Paspalum notatum) e o mio-mio (Baccharis coridifolia). Em meio aos butiás se encontram duas espécies de garupá (Aloysia gratissima, Aloysia chamaedryfolia) e, com menor freqüência, indivíduos de aroeira-brava (Lithraea molleoides), aroeira-cinzenta (Schinus lentiscifolius), anacauíta (Schinus molle), coentrilho (Zanthoxylum fagara), veludinho (Guettarda uruguensis) e taleira (Celtis ehrenbergiana). Da família dos cactos, salientam-se a tuna (Cereus hildmannianus) e a arumbeva (Opuntia elata), além de duas espécies de Parodia ( $P$. columnaris, $P$. ottonis) e outras duas de Frailea ( $F$. castanea e F. phaeodisca).

Apesar do relevo movimentado e da altitude consideravelmente maior ${ }^{8}$, comparado às áreas

8 No Palmar do Coatepe, as altitudes variam de 130 a $185 \mathrm{~m}$. 


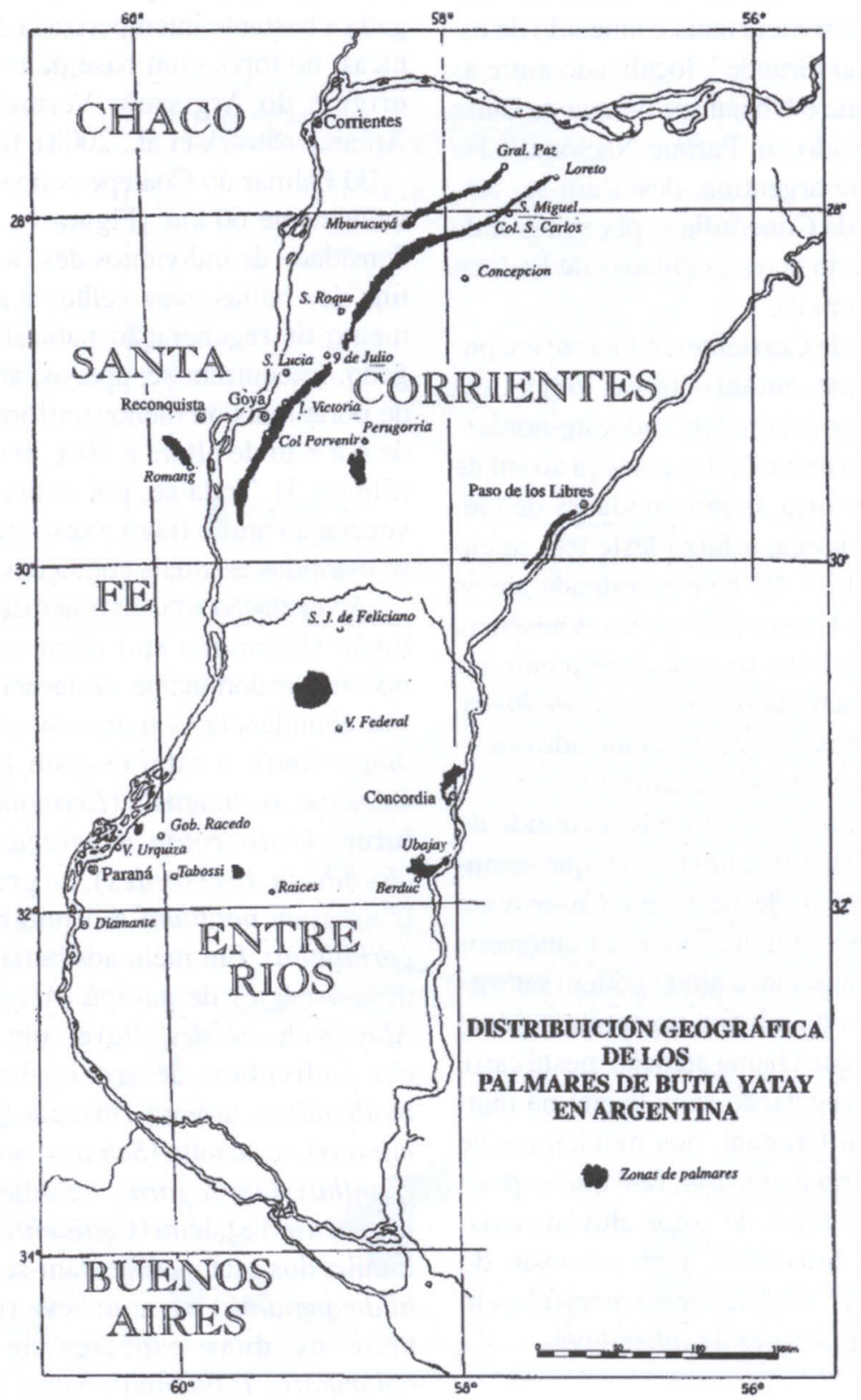

FIGURA 2 - Distribuição geográfica dos palmares de Butia yatay na Argentina. (Fonte: Crovetto \& Piccinini, 1951). 

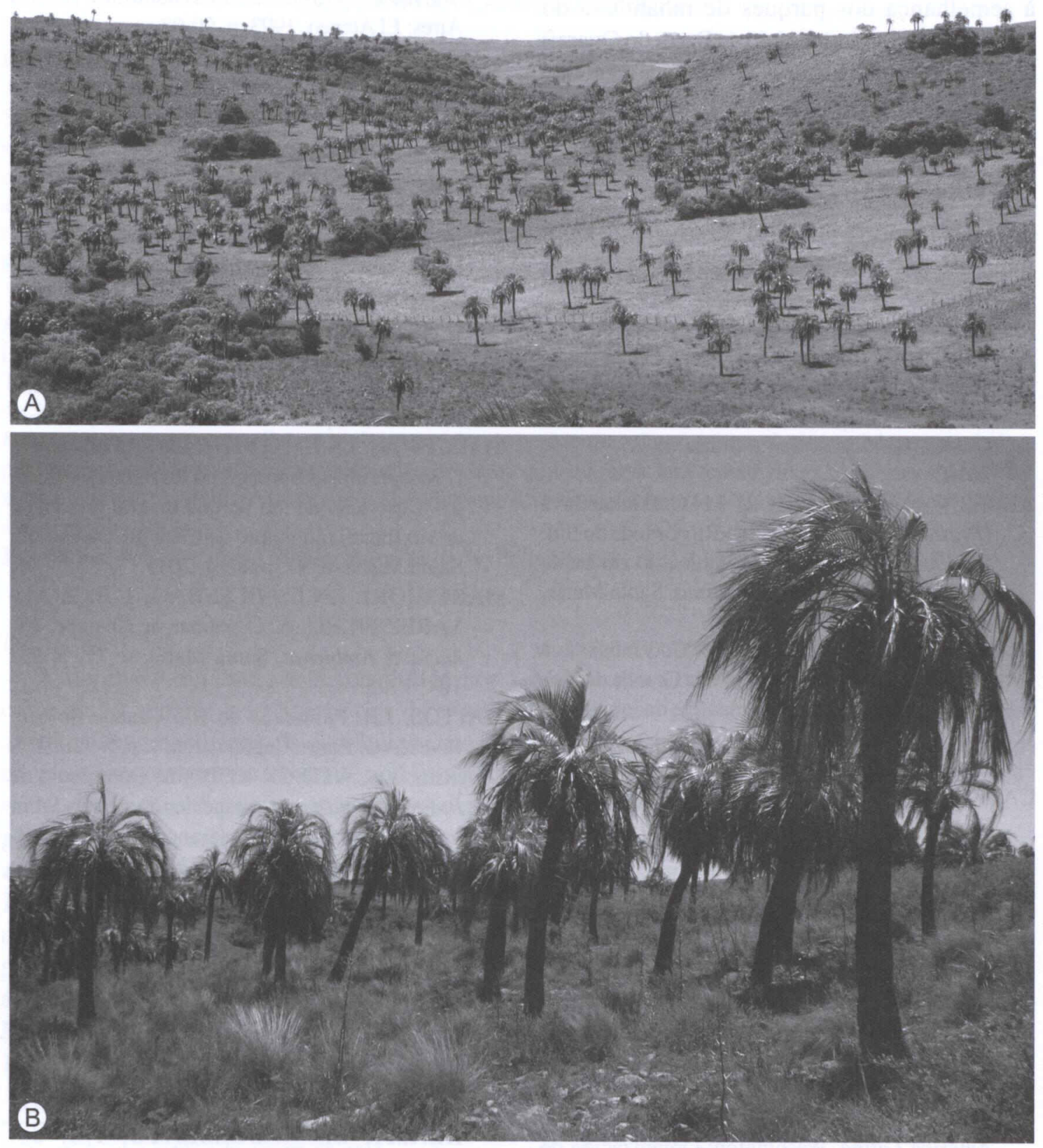

FIGURA 3 - Dois aspectos do Palmar do Coatepe, município de Quaraí. A - Vista geral do parque. B - Butiás adultos, em detalhe; notar a dominância do capim-limão (Elionurus sp.) no estrato herbáceo. 
de ocorrência na Argentina, o Palmar de Coatepe é de origem natural e vinculado a solos arenopedregosos, motivo pelo qual ele se inclui no Distrito do Inhanduvá e Província do Espinhal, à semelhança dos parques de inhanduvá do Pontal do Quaraí (município de Barra do Quaraí) e dos relictos de Prosopis affinis recentemente descritos na região do Jarau, município de Quaraí (Alves \& Marchiori, 2010), bem como no Loreto (Marchiori et al., 2010), e nas várzeas dos rios Santa Maria (Alves \& Marchiori, 2011A), Ibicuí (Marchiori \& Alves, 2011) e Itapororó (Alves \& Marchiori, 2011B).

\section{REFERÊNCIAS BIBLIOGRÁFICAS}

ALVES, F. da S.; MARCHIORI, J.N.C. O inhanduvá (Prosopis affinis Spreng.) no Rio Grande do Sul. 2 - Ocorrência natural na região do Jarau, Quaraí. Balduinia, Santa Maria, n. 25, p. 1-9, 2010.

ALVES, F. da S.; MARCHIORI, J.N.C. O inhanduvá (Prosopis affinis Spreng.) no Rio Grande do Sul. 5 - Ocorrência natural na várzea do rio Santa Maria, Rosário do Sul. Balduinia, Santa Maria, n. 27, p. 1-7, 2011A.

ALVES, F. da S.; MARCHIORI, J.N.C. O inhanduvá (Prosopis affinis Spreng.) no Rio Grande do Sul. 7-Ocorrência natural na planície de inundação do arroio Itapororó, município de Alegrete. Balduinia, Santa Maria, n. 28, p. 1-7, 2011B.

CABRERA, A.L. Territórios fitogeográficos de la Republica Argentina. Boletín de la Sociedad Argentina de Botánica, Buenos Aires, v. 4, n. 12, p. 21-65, 1951.

CABRERA, A.L. Esquema fitogeográfico de la Republica Argentina. Rev. Mus. La Plata, Botánica, v. 8, p. 87-168, 1953.

CABRERA, A.L. Fitogeografia de la Republica Argentina. Boletín de la Sociedad Argentina de Botánica, Buenos Aires, v. 14, n. 1-2, p. 1-42, 1971. (separata).

CABRERA, A.L.; WILLINK, A. Biogeografia de América Latina. Washington: Organización de los Estados Americanos, 1973. 120 p.

CROVETTO, R.M.; PICCININI, B.G. La vegetación de la Republica Argentina. 1. Los Palmares de
Butia yatay. Revista de Invest. Agríc., Buenos Aires, v. 4, n. 2, p. 153-242, 1951.

ERIZE, F; CANEVARI, M.; CANEVARI, P.; COSTA, G;; RUMBOLL, M. Los parques nacionales de la Argentina y otras de sus áreas naturales. Buenos Aires: El Ateneo, 1993. p. 90-92.

LORENZI, H.; NOBLICK, L.R.; KAHN, F.; FERREIRA, E. Flora brasileira: Arecaceae (Palmeiras). Nova Odessa: Instituto Plantarum, 2010. p. 183.

LORENZI, H.; SOUZA, H.M. de; COSTA, J.T. de M.; CERQUEIRA, L.S.C. de; FERREIRA, E. Palmeiras brasileiras e exóticas cultivadas. Nova Odessa: Instituto Plantarum, 2004. p. 123. MARCHIORI, J.N.C.; ALVES, F. da S.; PAZ, E.A. O inhanduvá (Prosopis affinis Spreng.) no Rio Grande do Sul. 3 - Parque da Cabanha do Loreto, São Vicente do Sul. Balduinia, Santa Maria, n. 25, p. 22-31, 2010.

MARCHIORI, J.N.C.; ALVES, F. da S. O inhanduvá (Prosopis affinis Spreng.) no Rio Grande do Sul. 6 - Descrição de um parque natural na várzea do rio Ibicuí, município de Cacequi. Balduinia, Santa Maria, n. 27, p. 8-14, 2011.

MARCHIORI, J.N.C.; ELESBÃO, L.E.G.; ALVAREZ FILHO, A. O palmar de Coatepe. $\mathrm{Ci}$ ência \& Ambiente, Santa Maria, n. 11, p. 93104, 1995.

MATTOS, J.R. Palmeiras do Rio Grande do Sul. Roessleria, Porto Alegre, v. 1, n. 1, p. 5-94, 1977.

SOARES, K. ; WITECK NETO, L. Ocorrência de Butia capitata e outras espécies do gênero Butia na região central do Rio Grande do Sul, Brasil. In: GEYMONAT, G.; ROCHA, N. M'Botiá: Ecosistema único en el mundo. Montevideo: Casa Ambiental, 2009. p. 37-41.

SOBRAL, M.; JARENKOW, J. A.; BRACK, P.; IRGANG, B.; LAROCCA, J.; RODRIGUES, R. S. Flora arbórea e arborescente do Rio Grande do Sul, Brasil. São Carlos: RiMA; Novo Ambiente, 2006. 350p.

STRECK, E.V.; KÄMPF, N.; DALMOLIN, R.S.D.; KLAMT, E.; NASCIMENTO, P.C. do; SCHNEIDER, P.; GIASSON, E.; PINTO, L.F.S. Solos do Rio Grande do Sul. Porto Alegre: EMATER/RS-ASCAR, 2008. 222p. 